\title{
Standards of healthcare and respecting children's rights
}

Roger Worthington

J R Soc Med 2006;99:208-210

Standards of healthcare develop over time in relation to a range of factors including social and political, and ethical and legal. As standards evolve they are influenced by factors that combine in particular ways at particular points in time, and the focus of this paper is on two of these primary factors, ethical and legal, particularly as they apply to the sector of the population that is under the age of 18 .

\section{THE QUESTION OF STANDARDS}

There is a process involved in setting the standards whereby clinicians come to be judged by patients, peers, employers and the courts. Setting standards is not just about determining cases where care has been sub-standard or negligent; it is part of a broader agenda, and, from the point of view of both public safety and public expectation, lead bodies have an obligation to try and define what is or is not acceptable. Ideally, standards need to be reactive to changes in the law as well as proactive in upholding and improving standards of care; in sum, what is needed are safe, acceptable professional standards that are measurable and achievable in what are often sub-optimal conditions.

In the case of children, standards need to be generic in nature because the population group in question is so diverse. There has been much public attention directed towards paediatrics in recent months ${ }^{1}$ (viz. cases involving David Southall and Roy Meadows that received wide media coverage in the UK c. 2003-2005). However, surgeons, anaesthetists, neurologists, psychiatrists and trauma specialists, for instance, are all likely to have regular contact with children and young people. It may not be advisable to leave law and ethics training about children to the specialist, postregistration stage, by virtue of the fact that standards and ethics for children's healthcare address such fundamental issues. If possible, this should be incorporated into undergraduate training, and, on account of national and international developments (see below), now would seem to be a good time to be considering some of the ethical and legal issues affecting children's healthcare. It is not without interest that the General Medical Council is responding to this challenge and is in the process of developing new guidance with a specific focus on children. ${ }^{1}$

Healthcare Law and Ethics Lead, School of Medicine, Keele University, Keele, Staffordshire ST5 5BG, UK

\section{CHILDREN'S RIGHTS}

In considering some of the underlying assumptions about rights, it has to be remembered that the under $18 \mathrm{~s}$ lack full personal autonomy. ${ }^{2}$ Decision-making for the under $18 \mathrm{~s}$ is not the same as for the general adult population: and it cannot just be assumed that clinicians will know the law or be able to recognize and respond instinctively to matters concerning children's rights. Awareness raising and educational input may be required when it comes to seeing robust ethical and legal standards of professional care as the norm. (In Scotland the age below which decisions may be challenged in the courts is 16 not 18.)

Since 1991 children's services in the UK have been under the umbrella of the UN Convention on the Rights of the Child (1989). More specifically, once fully implemented, children's healthcare will be covered by the Children Act (2004), and by National Service Frameworks (NSFs). (NSFs are not yet operative in all parts of the UK.) The overall setting for healthcare service delivery in the UK may fall within the NHS; but service provision for children and young people is part of a multi-agency enterprise, and all parts of this enterprise need to show recognition for the rights of the child. Hopefully too they will communicate with each other.

Difficulties can arise that have a social dimension, and guidance has to tread a line between acting in the public interest, and acting in the best interests of young and vulnerable individuals. Ethical considerations should take centre stage, trying to balance interests that may be pulling in different directions; and it is unlikely that the law will ever be so prescriptive as to set out details covering every possible situation. Clinical judgment needs to incorporate an understanding of legal and ethical issues in a way that extends further than simply providing care for individual young patients.

The clinician works as part of a team, and the clinical team has to interact with other agencies: but it is not always easy for agencies with different working cultures to pull together and work towards common goals that ought to be about the safety and well-being of the child. A hierarchy of rights and obligations may have to be applied in difficult situations, and sometimes these situations demand immediate action. If rights conflict it takes more than a dose of common sense to determine which right takes precedence over which and when. 
The Children Act $2004^{3}$ covers all forms of service provision (i.e. not just medical), and while it creates a new starting point in terms of common law it leaves practical details to be worked out later on. ${ }^{4}$ It does not directly address questions of autonomy and consent, and although with competent adults respect for autonomy should be regarded as a right, autonomy for the under $18 \mathrm{~s}$ is not a well-defined concept and it can be challenged in a number of ways. Therefore, with children and young people it is more meaningful to talk about respect for rights than merely respect for autonomy. One may be an expression of the other but they are not the same concept.

To take an example, the debate about autonomy, consent and attitudes towards underage sexual activity has once again become subject to scrutiny, pending a judicial review of guidelines issued by the Department of Health. ${ }^{5}$ Discussion about confidentiality and reproductive advice for the under 16s harks back to the Gillick judgment of $1985 ;{ }^{6}$ and while the law has evolved since then, it is hard to dispute the fact that rights of parents and rights of children can conflict with each other. Clinicians may be sitting in the middle, and while children's rights can and should be respected, the extent of the autonomy of the child may well be difficult to determine.

Where there are competing interests it could require skills of a multi-professional team fully to establish what is in the best interests of a particular child. Although young children may be increasingly involved in clinical decisions, even if at a fairly rudimentary level, powers of decisionmaking are relative to age and maturity. This is perfectly sensible even though, perversely, reaching the age of 18 means that powers of decision-making cease to be about rationality. ${ }^{7,8}$ (The competent adult can refuse any kind of treatment for no reason at all, the criterion for adult participation being competence not rationality.) It is not just a question of who decides - the responsible adult, the child or the clinician. All three have a role to play that can only reasonably be determined by circumstances surrounding an individual case.

Questions often arise to do with trust, communication, and levels of responsibility about how best to safeguard children and protect them from harm and abuse. These cannot be fully discussed here, but a question of utility that should not be overlooked concerns whether it is ever right knowingly to risk harm to one child in the interests of protecting known or unknown others. National and international law is clear in stating that the best interests of the child must be paramount. ${ }^{9}$ But these interests are not always easy to ascertain, and since each case can only be assessed on its merits one cannot stipulate in advance what course of action would result in greater harm or what would or would not be in the best interests of a particular child.
If a public interest argument is persuasive then the emphasis is going to switch from the individual to the community. Society takes the view that it is just and proper to lock up adults who pose a threat to others, whether for reasons of mental health or for exhibiting criminal, dangerous behaviour. But this too is more difficult with children and leads into a parallel debate about the age of criminality. Society has a collective interest in protecting children. (Wales is reviewing all of its procedures for safeguarding children. ${ }^{10}$ ) Those charged with carrying out this task have to steer a course between protecting public interests and upholding the rights of individual parents and children, and it will be interesting to observe their findings (the report is due to be published in December 2005).

\section{CONFIDENTIALITY}

While most day-to-day clinical situations do not involve criminal or negligent behaviour, it would be unwise to assume simply that 'clinicians know best'. Children can be physically and/or psychologically harmed by unwise decisions, and this could include decisions about sharing information. Confidentiality is a basic tenet of good medical practice, but situations exist where it has to be sacrificed either in the interests of the community, or in the interests of someone in need of protection afforded by social services, say from a dangerous or abusive parent. While one cannot know what information needs to be shared until a case has been made to share it, it is wrong simply to assume that confidentiality no longer matters.

Children have a right to medical confidentiality, even if more instances exist where it might have to be overridden than would apply normally in the case of adults. Once private and confidential information has been released it cannot then be retracted. Therefore, too much disrespect for medical confidentiality and children and young people could so easily lose trust in those professionals best placed to provide practical help and advice. A balance here must be found between competing claims over who has access to what information and when, and the mantra of sharing information all of the time is not risk free.

Another important question concerns what happens when a child or young person feels his/her rights have not been respected. Rights are an illusion if the rights bearer does not know what rights exist: so this information must be public and readily accessible to children (e.g. [www.funkydragon.org]). For rights to be meaningful, children need to know what they are and who to turn to if/ when their rights are ignored. In this respect, offices of the Children's Commissioners currently being established throughout the UK, should help to provide a safety net for children in need of advocacy and support needing to know where to turn (e.g. if a school fails adequately to 
address concerns about bullying). This is still fairly new territory, and a review into advocacy, in the context of local education by the Children's Commissioner for Wales (2005), could usefully be assessed for relevance within the health care setting. ${ }^{11}$ (Commissioners in each of the four countries have slightly different powers, but the general concept is the same- - see [www.everychildmatters.gov.uk/ strategy/childrenscommissioner].) Only if rights for children are taken seriously does a concept such as advocacy really come to the fore.

\section{CONCLUSION}

Rights for children imply obligations on adults, and how these obligations are satisfied and what measures are in place when they need to be spelt out. Best practice standards may not be achievable all of the time, and while the practising professional needs a measure of protection from unjust accusations about poor practice, a wellqualified and articulate adult is almost certainly better able to self-protect than a child or young person being abused.

On the other side to the coin, clinicians have to take care not to make false assertions about parents. This can be almost as damaging to children as failing to organize adequate protective measures. Quite rightly, sanctions are applied in the case of any medical practitioner who is shown to pose a danger to patients or to the wider public. ${ }^{12}$ However, boundaries of unacceptable professional conduct are not always easy to define. Besides legal arguments about burden of proof, in a case where doubt exists as to the nature of what did or did not take place, then well researched guidance should help provide a reliable benchmark for assessing competence. Given heightened sensitivity towards case involving the care of children, this is not without relevance to the present discussion.

Guidance should allow those in training and the majority of medical practitioners who do their job well to know what standard is expected of them and how best to try and achieve that goal. Poorly defined standards can pose a threat to public safety and confidence, and this is never more pertinent than where children and young people form the group of patients in question. It is time now for children's rights to command universal recognition and respect and for them to become a practical reality in the domain of everyday clinical practice.

Acknowledgments Thanks are due to Jane O'Brien (Head of Standard and Ethics at the GMC) and Professor Ian Butler (Cabinet advisor on children's affairs to the Welsh Assembly) for their advice and comments.

Note: This paper was presented at the Association of Medical Humanities 3rd Annual Conference, July 2005, Royal Cornwall Hospitals NHS Trust, Truro, Cornwall, UK.

Competing interests $\mathrm{RW}$ is an advisor on standards and ethics at the GMC, London, for which he receives payment. No grants or other monies were sought or obtained.

\section{REFERENCES}

1 GMC Today April 2005

2 Royal College of Physicians. Ethics in Practice, Working Party Report 2005 [www.rcplondon.ac.uk/pubs/ClinicalMedicine/index]

3 The Stationery Office [www.opsi.gov.uk/acts.htm]

4 DfES Change for Children [www.dfes.gov.uk/ISA/keepUpTodate/ calendar.cfm]

5 Department of Health. Summary: Best Practice Guidance For Doctors And Other Health Professionals On The Provision Of Advice And Treatment To Young People Under 16 On Contraception, Sexual And Reproductive Health. [Gateway Ref. No. 3382. London: DoH, July 2004]

6 Gillick v West Norfolk \& Wisbech Area Health Authority (1985) [3 All ER 402]

7 Re B Consent to treatment (2002) [2 All ER 449]

8 Cf. Adults with Incapacity (Scotland) Act, 2000, and Mental Capacity Act (2005) section 1.4: 'A person is not to be treated as unable to make a decision merely because he makes an unwise decision'

9 Cf. Children Act (1989); United Nations Convention on the Rights of the Child (1989)

10 Review ordered by Cabinet sub-committee for Children and Young People, Wales (2004) [http://www.wales.gov.uk/organicabinet/ SubCmteeMeetings/children/index.htm]

11 Children don't Complain [http://www.childcomwales.org.uk]

12 GMC Guidance on problem doctors [http://www.gmc-uk.org/ probdocs/default.htm] 